INNOVATIONS IN PRIMARY CARE

\title{
Medical School Affiliation Accelerates the Development of Community Health Centers in China
}

\author{
Xiaoting Sun, $P b D$ \\ Chenghua Jiang, MD \\ Xinxin Zhao, MS \\ Han Zhang, MD \\ Yiban Chen, MD \\ Jialin C. Zheng, MD \\ Jue $L i, P b D$
}

Ann Fam Med 2021;19:178. https://doi.org/10.1370/afm.2657.

\section{THE INNOVATION}

At Tongji University School of Medicine we established affiliation relationships with community health centers (CHCs) in Shanghai, which was unprecedented in China. During the process, we assisted CHCs in strengthening their portfolio through the improvement of public trust, working environment, health care process and quality, professional development, clinical rotations, and community-oriented research.

$\mathrm{CHCs}$ are the cornerstones of the primary care system in urban China. Due to many historical reasons, CHCs' gatekeeper roles are hindered by hospital dominance, and lack of quality clinicians, resources, and public trust. As the "manufacturers" of health care clinicians and the academic center of the family medicine discipline, medical schools are responsible for educating high-quality family physicians currently highly needed in our society. Strengthening CHCs to create better training experiences and appealing career paths for medical graduates is vital in guiding them to choose primary care. ${ }^{1}$

\section{WHO \& WHERE}

We are Tongji University School of Medicine, located in Shanghai, China. We have 3 campuses for undergraduate education and rich clinical resources, including 14 affiliated hospitals, more than 20 training bases, and 12,000 hospital beds. We started community collaboration in 2017 and received applications from 22 CHCs in Shanghai. Thirteen centers located in 6 districts were qualified and launched the affiliation process, 7 have successfully acquired affiliation, and the rest are in progress.

Conflicts of interest: authors report none.

\author{
Corresponding author \\ Jialin C. Zheng \\ 301 Middle Yanchang Road \\ Shanghai Tenth People's Hospital \\ Tongji University School of Medicine \\ Shanghai 200072, China \\ jialinzheng@tongji.edu.cn
}

\begin{abstract}
HOW
The affiliation process included several steps. First, clear standards (Supplemental Table 1) were set for evaluating CHCs on their clinical performance, faculty development, and teaching conditions for qualification. Second, field investigations were conducted to grade the baseline status of CHCs. Third, detailed goals and improvement plans were established collaboratively. Finally, CHCs were reevaluated with the same standards after at least 1 year of continuous improvement. Those who reached their goals of improvement were granted the affiliation certifications and contracts were signed to stipulate mutual responsibilities.
\end{abstract}

\section{LEARNINGS}

Being the first academic institution in China to actively collaborate with $\mathrm{CHCS}$, we recognized many unique mutual benefits and progress in performance (Supplemental Table 2). Academic affiliation increases public trust towards CHCs because it implies reliable health care quality and resources, resulting in increased numbers of outpatient visits and contracted services. Second, we provide $\mathrm{CHCs}$ with academic and clinical resources that were unavailable from their administrative district health commissions. CHCs now have access to advanced faculty training under the collaborations we established with world-renown academic primary care institutions. Specific funds are provided to support community-oriented research projects. Specialists in affiliated tertiary hospitals serve as extended team members to facilitate disease management in CHCs. Third, family physicians gain expanded career development in affiliated $\mathrm{CHCs}$, by being our faculty members and practicing at multiple sites in the affiliated tertiary hospitals. Moreover, the teaching volume increased in CHCs allowing more preceptors to be trained. Medical students and family medicine residents are provided with expanded opportunities for their clinical rotations in affiliated CHCs. Lastly, we connect the affiliated CHCs and conduct multicenter population-level studies, which would inversely guide clinical practices in the community. This affiliation initiative has been adopted in Shanghai municipal government's guidelines for promoting family medicine through employing medical schools' advantages. ${ }^{2}$ With governmental support, we believe this innovative approach led by medical schools can accelerate grassroots primary care facilities' development and transform patients' care-seeking behaviors gradually.

Supplemental material including author affiliations, key words, acknowledgments, references, and supplemental tables are available at https://www.AnnFamMed.org/content/19/2/178/suppl/DC1/.

Submitted May 8, 2020; submitted, revised, August 8, 2020; accepted August 10, 2020. 